\title{
PSYCHE
}

VOL. XLI

DECEMBER 1934

No. 4

DESCRIPTIONS OF THREE NEW NORTH AMERICAN ANTS WITH CERTAIN ECOLOGICAL OBSERVATIONS ON PREVIOUSLY DESCRIBED FORMS

\author{
By William Steel Creighton \\ College of the City of New York
}

Myrmica (Manica) parasitica sp. nov.

Worker: Length; $5 \mathrm{~mm}$.

Head exclusive of the mandibles quadrate, as broad as long, the sides and occipital border feebly convex, the occipital angles broadly rounded. Anterior border of the clypeus entire, angular, the portion in front of the median lobe flat, the lateral portions at either side straight but receding toward the insertions of the mandibles. Median lobe of the clypeus strongly convex in two planes, sharply separated from the large, triangular frontal area. Mandibles large and powerful, the external border rather feebly convex except near the tip where it turns inward sharply. Masticatory margin armed with a long, sharp and rather thin terminal tooth and a much shorter and stouter subterminal tooth; the remainder of the masticatory margin bearing 12 - 15 small teeth. Frontal carinæ short, thick, bluntly pointed in front and rather widely separated. Antennal scapes short and rather thick, strongly and abruptly curved at the base; in repose the tip of the scape surpasses the occipital border by an amount less than its greatest thickness. First funicular joint longer than broad and somewhat broader than the adjacent joint, joints $2-6$ gradually increasing in diameter and length, the four apical joints 
together form a distinct club whose maximum diameter is about three times that of the preceding joints. Eyes oval, moderately convex, set at the middle of the side of the head.

Thorax in profile with the promesonotum rather feebly convex, the promesonotal suture not impressed. Mesoepinotal suture prominent but with a shallow impression on the thoracic dorsum which is principally due to the elevated anterior edge of the epinotum since the posterior face of the mesonotum slopes directly to the suture without any impression. Epinotum in profile with a very feebly convex basal face which passes to the shorter declivious face through a poorly marked and very wide angle. In some specimens the angle between the two faces is virtually eliminated so that the profile of the epinotum is a single, convex, descending slope. Seen from above the promesonotum is pyriform and only a little wider than the subpentagonal epinotum. The sides of the thorax are only slightly constricted at the mesoepinotal suture.

Petiole seen in profile with a node which is very low, broadly and evenly convex above and without sharp transitions to the anterior or posterior peduncles. The ventral tooth on the anterior peduncle is very variable in character, In some specimens it is reduced to an angle, in others it has the form of a blunt, short tooth, in still others it is a very long and slender recurved spine. Dorsum of the postpetiole in profile with a long, sloping, feebly convex anterior face and a very short vertical posterior face. Ventral surface of the postpetiole in profile evenly convex. Seen from above the petiole is narrow and spindle shaped with the anterior peduncle slightly thinner than the posterior peduncle. The postpetiole has the form of a truncated cone with the sides convex. It is a little less than twice as wide as the node of the petiole.

Gaster bulky, oval.

The sculpture of this insect, particularly that of the head, shows considerable variation. In some specimens the entire head is covered with fine, longitudinal striæ. The more 
lateral of these curve downward under the antennal fossæ and are carried forward to the insertion of the mandible. In such specimens the head is feebly shining with a semimatte appearance. In other specimens the striæ are almost entirely absent being represented by a few on the posterior parts of the frontal carinæ and others on the side of the head between the eye and the insertion of the mandible. In such specimens the remainder of the head is highly glabrous with numerous, small piligerous punctures. The same variability is true to a lesser extent of the thoracic sculpture. In some specimens the entire thorax is covered with fine punctures which grade into longitudinal striæ on the pleuræ. Such specimens are feebly shining. In other specimens the whole thorax is highly glabrous, entirely without sculpture except for a few feeble lines or punctures at the base of the pleuræ, The sculpture of the petiolar nodes is more constant since even in the heavily sculptured individuals, these are in large part glabrous. Abdomen smooth and shining with fairly numerous small piligerous punctures.

In color and pilosity the insect is more uniform. The head is piceous with the mandibles a somewhat more brownish black and having a wide band of sordid yellow extending along the masticatory margin. Thoracic dorsum blackish brown, the pleuræ of the pronotum clear, brownish yellow, the pleuræ of the mesonotum and epinotum a clear brown which is somewhat lighter on the declivious face of the epinotum. Petiolar nodes blackish brown. Abdomen a darker brown than the petiolar nodes but not as black as the head. The entire insect covered with rather long, slender, curved hairs which are pointed, erect and yellowish in color. These are most abundant on the head particularly on the ventral surface where they form poorly developed gular ammochætæ. Flexor surface of the femora with a row of stiff, erect bristles. Extensor surface of the femora, tibiæ, tarsi, antennal scapes and the proximal half of the funiculi covered with small, fine reclinate hairs. Clubs of the funiculi pubescent. 
Host: Myrmica (Manica) bradleyi Wheeler.

Types in my collection and in the collection of Dr. W. M. Wheeler.

The series of workers upon which this species is based was taken on the summit of Polly Dome (elevation about 8600 feet), a small dome adjacent to Tenaya Lake on the Tioga Pass road in the upper part of Yosemite National Park, California. Because of glacial action the domes have precipitous sides planed to a high degree of smoothness. It is actually possible in certain lights to see a glaze on the surface, which resembles that of a polished terrazzo floor. Naturally, the domes themselves are not good areas for collecting since there is very little soil present and when any does occur it is usually in pockets of coarse gravel and sand not suitable for nest making. Despite such unfavorable conditions the nest containing the new species was found in one of these gravel pockets. When first discovered only five parasitica workers were taken since, at that time, the author had nothing with which to excavate the nest. These five workers together with a number of workers of the host, bradleyi, were taken back to camp alive and the relations between the two species observed. These were to every appearance perfectly normal, the parasitica workers taking their share of the activities and being treated as ordinary nest mates by the bradleyi workers. The following day the author returned to the nest site and excavated the entire gravel pocket, luckily a small one, down to bed rock. Eight more parasitica workers were secured but no queen of any kind was seen. I am of the opinion that she may have moved to a safer place following the initial disturbance of the nest since, due to the ease and completeness with which the gravel could be removed and sorted, it is curious that she should have been missed had she been present. The failure to find the queen is much to be regretted since her structure might have shed some light on the type of relation between the host and parasitica. As the matter stands at present it is impossible to state with certainty whether the new species 
is a slave maker or a temporary social parasite. In view of the fact that parasitica is smaller than bradleyi and has no mandibular specialization which might offset this disadvantage it seems more likely that the new species is a temporary social parasite.

Because of the close correspondence of general morphological characteristics it can scarcely be doubted that parasitica has been derived from bradleyi. It differs from bradleyi, however, in the following respects: the epinotum is lower and less angular, the node of the petiole is lower and more rounded, the sculpture is more feeble as even the most heavily sculptured individuals of parasitica never approach the heavy sculpture characteristic of bradleyi, the thorax and petiolar nodes are black (reddish yellow in bradleyi), the hairs are stouter, more uniformly erect and considerably more numerous on the ventral surface of the head.

Aphaenogaster (Attomyrma) huachucana sp. nov.

Worker: Length: 4.5-7 mm.

Head exclusive of the mandibles one and one half times as long as broad, the sides subparallel in the anterior twothirds but narrowing sharply in the posterior third. Occipital border flat, less than half as wide as the greatest width of the head and bordered by a narrow but very distinct reflected flange. Clypeus moderately projecting, the anterior border sinuate with the median impression in some specimens broad, shallow and evenly concave, in others deeper, and more narrow with a distinct notch in the middle. Median lobe of the clypeus rather flat, ecarinate, not sharply marked off from the lateral portions and with an evenly rounded posterior border between the frontal carinæ. Frontal area only slightly depressed, shining with a prominent median carinula. Mandibles slender, the external margin straight except near the tip where it turns inward sharply and is convex. Outer third of the masticatory margin armed with three prominent teeth which decrease in length from the terminal tooth inward, the remainder of the mas- 
ticatory margin irregularly serrate. The straight inner margin of the mandible meets the masticatory margin at a sharply marked angle. Eyes oval, of moderate size and rather strongly convex with their posterior borders lying slightly in front of the middle of the side of the head. Frontal carinæ prominent and subparallel, their lateral portions in the anterior half turned upwards so that from above this part of the carina appears narrow and welt-like. Antennal scapes long, slender and evenly though slightly curved outward. In repose they surpass the occipital border by one-third their length. The base of the scape is strongly spatulate. Funiculus filiform, joints $1-7$ all of about the same length and diameter and all several times longer than broad, joints $8-12$ somewhat broader than the preceding joints and slightly increasing in diameter apically.

Dorsum of the pronotum in profile feebly convex. Just posterior to the promesonotal suture the mesonotum is abruptly elevated. This elevated portion, which is flat on top, occupies the anterior half of the mesonotum and passes to the posterior half through a short and abruptly descending declivity. The posterior half of the mesonotum, which is also flat on top, is slightly if at all higher than the adjacent portion of the epinotum from which it is separated by a narrow U-shaped impression at the mesoepinotal suture. Epinotum in prosile angular, the basal face, which is straight and slopes slightly to the rear, twice as long as the almost perpendicular declivious face. The angle between the two faces is armed at either side by a short, rather blunt tooth with a very wide base. Seen from above the pronotum is subpentagonal with the lateral portions carried back past the anterior half of the mesonotum so that the latter has the appearance of being a part of the pronotum. Just behind the pronotum the sides of the mesonotum are slightly constricted. There is no constriction of the sides at the mesoepinotal suture other than the very shallow incision formed by the suture itself. Seen from above the dorsal face of the epinotum bears a shallow longitudinal sulcus extending 
backwards between the teeth. This sulcus is bordered at either side by a ridge which extends forward from the base of each tooth.

Node of the petiole in profile with a straight, sharply sloping anterior face which meets the anterior peduncle at a wide but well-marked angle. Summit of the node blunt, the posterior face slightly convex and steeply descending to the very short posterior peduncle. There is no ventral tooth on the anterior peduncle but a narrow lamella runs almost its entire length. Postpetiole in profile notably larger than the node of the petiole, its dorsum consisting of a long, sloping anterior face, a rounded summit and a shorter and more declivious posterior face. The ventral face of the postpetiole is straight or feebly sinuate. Seen from above the node of the petiole is subcircular, about twice as wide as the anterior peduncle and a little more than half as wide as the pyriform postpetiole.

Gaster rather small, oval.

Mandibles moderately shining, covered with fine and somewhat irregular longitudinal striæ. Entire head, except for the frontal area and the antennal fossæ, feebly shining or dull, coarsely reticulo-rugose with the interrugal spaces finely granulose. Just above the insertion of the mandibles and on the clypeus the granulation is more feeble than elsewhere. In some specimens the median lobe of the clypeus lacks the granulation altogether. Antennal scapes finely and densely punctate. Thorax densely and rather more coarsely granulose than the head. In certain lights feeble rugæ may be seen on the thorax, especially on the epinotum where they are most prominent. None of them, however, are nearly as well developed as those on the head. Petiolar nodes finely granulose. Abdomen glabrous with exceedingly fine, piligerous punctures.

Hairs moderately numerous, rather short, coarse, golden, erect and somewhat obtuse. About equally numerous on all parts of the body. Femora with short, rather sparse, erect hairs: those on the tibiæ and tarsi more numerous, finer and 
suberect or appressed. Antennal scapes with numerous, very fine, appressed hairs; those on the funiculi longer, stouter and suberect except on the four terminal joints where the erect hairs are replaced by pubescence.

Color: head, thorax and petiolar nodes rich reddish brown to yellowish brown; the mandibles, legs and abdomen brownish yellow to clear yellow.

Described from a series of ninety workers taken in Ramsey Canyon, Huachuca Mountains, Arizona, at an elevation of 7000 feet.

Types in my collection and in the collection of Dr. W. M. Wheeler.

There can be little doubt that huachucana is closely related to texana, particularly to the variety furvescens Wheeler. Despite the fact that furvescens was originally described from material taken in Ramsey and Miller Canyons in the Huachuca Mountains I have no hesitancy in regarding huachucana as a distinct species since the structural peculiarities which it shows are reinforced by pronounced ecological differences. On the basis of structure the most obvious difference in the two species lies in the greater size of the new form (4.5-7 mm. in huachucana, 4-5.5 $\mathrm{mm}$. in furvescens). In addition the head of huachucana is of a different shape. This is due largely to the fact that the sides in the narrowed posterior third are less convex, the occipital border narrower and the flange which borders the latter more pronounced in the new species. The antennal scapes in huachucana are notably longer than those of furvescens and are strongly spatulate at the base, a feature not present in the scape of the latter form. In the thorax of huachucana the anterior half of the mesonotum is more sharply set off from the adjacent portions of the thorax, particularly behind where there is a definite descending posterior face not found in the thorax of furvescens. The character of the epinotal spines is quite different in the two forms. In huachucana these are short and very broad at the base so that they are more aptly regarded as angular 
teeth than spines. In furvescens the spines, while only slightly longer than those of huachucana, are slender throughout and not tooth-like. Finally the sculpture of huachucana is uniformly heavier than that of furvescens.

The ecological differences are equally distinct. The nest from which the types of huachucana were secured was situated at the base of a rocky ledge above a very steep slope on the western side of the canyon. The arrangement was such that the nest was in the shade for the greater part of the day. The elevation, as has been already noted was 7000 feet. I have taken many colonies of furvescens both in Ramsey and Miller Canyons. These were invariably under stones in sunny situations not far removed from the stream bottom and at elevations not exceeding 6000 feet. Finally the actions of huachucana are quite different from those of furvescens. The insects are slow, one might almost say clumsy, in movement even when excited, a marked contrast to the active and energetic workers of furvescens.

On the last day of May 1932 one of my students, Mr. Solomon Friedland, while collecting along the top of the Palisades near Englewood, N. J. had the good fortune to secure a single female belonging to the genus Anergates. At that time I considered the insect identical with the European atratulus but subsequently, through the generosity of Dr. W. M. Wheeler, I have been enabled to compare it with specimens of atratulus collected by Dr. Wheeler in Switzerland. This comparison has revealed a surprising number of significant differences and I now feel that the insect taken by Mr. Friedland must be regarded as a new species. Mr. Friedland's discovery is of twofold interest for it not only gives us first record of Anergates in the New World but also furnishes important data on the distributional status of the host species Tetramorium cxspitum. This matter is discussed in detail at the end of the following description.

Anergates friedlandi sp. nov.

Female: Length: $2.2 \mathrm{~mm}$. (the gaster not expanded) 
Differing from the female of atratulus in the following characteristics :

The single mucronate point with which the mandible is armed longer and stouter; the convex masticatory border of the mandible very feebly serrate (smooth in atratulus). Eyes nearly circular in outline and strongly convex with rather fine facets (oval and moderately convex with coarse facets in atratulus). Lateral ocelli small and so placed that they are hidden when the head is viewed from directly in front by the rectangular occipital crest on which they are borne (lateral ocelli larger and distinctly visible from the front in atratulus). Antennal scapes slightly and evenly curved outward, gradually increasing in thickness from base to apex and in repose surpassing the occipital border by an amount equal to the greatest thickness (in atratulus the scapes are almost straight, thickest at a point about threequarters of the distance to the apex and in repose surpassing the occipital border by an amount less than their greatest thickness). Seen from above the epaulet-like lateral portions of the pronotum are strongly concave, blunted behind and set off from the median portion of the pronotum by a rounded welt or ridge (in atratulus the lateral portions of the pronotum are only slightly concave, rather sharp behind and set off from the median portion of the pronotum by a sharp ridge). Scutum longer than in atratulus and with more overhang at the anterior edge. The posterior portion of the scutum is evenly depressed all the way across including the paraptera so that there is a sharp transition to the scutellum when the thorax is viewed in profile (in atratulus the depression of the scutum is median only, the paraptera not being depressed, so that there is a sort of a shallow trough formed on the dorsum of the thorax; however in profile the transition between the scutum and scutellum appears less abrupt because of the elevation of the paraptera above the level of the middle of the scutum). Scutellum narrower and much more convex than in atratulus. Epinotum seen from above with the lateral projections less prominent and 
more rounded than in atratulus. Seen from behind the broad longitudinal impression on the posterior face of the epinotum is broadly rounded above (narrower and rather pointed above in atratulus). Seen in profile the node of the petiole has a definite, short posterior face, a rounded and rather narrow summit and a long steeply sloping anterior face. Although both posterior anterior peduncles are short both are distinctly visible in profile and sharply set off from the node (in atratulus the node of the petiole is much bulkier with the dorsum broad and obtusely angular. The anterior and posterior peduncles are so short as to be virtually invisible when seen in profile). Postpetiole seen from above thinner from front to back than in atratulus with the anterior edge much less convex. The dorsum bears a shallow, median longitudinal sulcus (entire in atratulus). Abdomen with a deep median sulcus as in atratulus.

Sculpture very finely and evenly punctato-rugose except the very deeply notched clypeal border, the mandibles and the appendages which are shining. The sculpture is uniformly heavier than in atratulus, particularly on the posterior abdominal segments where it renders the surface definitely opaque (feebly shining in atratulus).

Color: head and thorax blackish brown, gaster a somewhat clearer brown, appendages dirty yellow. Wings hyaline, covered with numerous small hairs, the veins and stigma pale yellow.

Type in my collection.

It is much to be regretted that this interesting insect is known only from a single specimen. Following Mr. Friedland's discovery I returned with him to the type locality, a small meadow at the side of U. S. Highway No. 9 about three miles north of Englewood, N. J. In this place there are many nests of Tetramorium cæspitum constructed in coarse, gravelly soil along the sides of a fill over which the highway runs. Although we examined a number of the nests and although, during the following spring, the site was revisited for more extensive observation, no additional specimens 
have been taken. This is scarcely surprising in view of the rarity of the European atratulus.

As has already been mentioned the presence of Anergates in North America presents some points of peculiar interest. In the Old World Anergates atratulus, a workerless parasite with degenerate, pupoidal males, is known to occur only in the nests of Tetramorium crspitum. There is no reason to suppose that the American species possesses a generically different host. However it has been generally held that the presence of Tetramorium cæspitum in this country has come about through introduction from Europe. In point of fact there is more than a little evidence in favor of such a view. In 1905 when Dr. W. M. Wheeler published a list of the ants of New Jersey (1) he outlined the range of T. cæspitum as follows: "It occurs northward and eastward of New York as far as the Connecticut boundary, westward as far as Philadelphia and southward as far as Virginia." In subsequent years Dr. Wheeler published two other faunal lists dealing with New England species. The first of these (2) which appeared in 1906 covered all the New England states. In this paper there is a single record of cxspitum based on material taken by Dimmock at Spring ield, Mass. The second of the lists mentioned above (3) appeared in 1916 and dealt with Connecticut only. In this paper Dr. Wheeler stated that cæspitum must certainly occur in Connecticut but he added that at the time of publication he had no actual records of the insect from that state. In 1927 Dr. Wheeler, reported (4) the first appearance of cæspitum in metropolitan Boston, In the same year I found several colonies of this ant along the paths of the Arnold Arboretum in Forest Hills. I have subsequently received specimens from Dr. Geo. Tullock taken at Bridgewater, Mass. Since cæspitum is by no means an obscure ant it follows that the virtual absence of New England records prior to 1929 can scarcely be credited to oversight on the part of collectors. For this reason its appearance in the vicinity of Boston in 1928 may be regarded as a migrational ingress. This is entirely in keeping with 
the character of an introduced species but is not easy to explain in the case of a native form.

All of the above evidence is, of course, negated by the discovery of an American species of Anergates. Under these circumstances to continue the belief that Tetramorium cxspitum is an introduced ant necessitates the assumption, that when introduced a nest of cxspitum contained specimens of Anergates and since the time of introduction Anergates has undergone sufficient change to rank as a separate species. The author finds neither point tenable and is therefore prepared to regard crspitum as a native member of our North American ant fauna. This bears out evidence presented by two of Emery's earlier records for cæspitum, one from Tennessee, the other from Nebraska. These records were always troublesome to the older view of crspitum as an introduced species since both lie well beyond the eastern range of the ant and are separated from it by areas in which cxspitum apparently does not occur. Such a distribution need occasion no remark in the case of a native form.

One additional point may be considered here. It is possible that the insect which we now regard as the North American representative of Tetramorium cæspitum may not be cospecific with the European form. As far as the author can ascertain there are no differences of specific significance but since crspitum shows a number of variants in Europe it is difficult to make a positive statement in this regard. However, even should the North American Tetramorium prove identical with one of the European forms of cæspitum its status as a native ant remains unaltered. One need only cite the case of Formica fusca to furnish an example of a holarctic host which supports specifically different parasites in the Old and New Worlds and whose distribution cannot possibly be the result of introduction.

\section{ECOLOGICAL NOTES.}

(1) An unusual slave of Formica sanguinea subsp. puberula Emery. 
During the summer of 1933 the writer had the opportunity of collecting in the La Sal Mountains in southeastern Utah, an excellent region of unusual scenic beauty. The area worked was in the vicinity of the Warner Ranger Station which is situated on the northwestern side of Mount Allen at an elevation of about 9500 feet. Most of the collecting was done at the upper edge of a sage brush area which covers a large part of the top of Wilson Mesa. At the elevation just mentioned the sage brush is stunted in size and occurs on exposed ridges between which there are valleys filled with aspen trees. In this aspen-sage brush association one of the most abundant ants is Formica sanguinea subsp. puberula Emery. Of the many colonies of this insect which the author examined one was unique in containing specimens of Formica microgyna subsp. rasilis Wheeler as slaves. In addition a second slave, Formica cinerea var. altipetens Wheeler, was present. This second slave need cause no comment since other forms of cinerea have been previously reported as enslaved by puberula. So far as I am able to determine, however, there is no previous record of the enslavement of any member of the microgyna group.

It may be seen that there are two explanations for the formation of the colony just described. The simplest assumption is that the rasilis workers had been brought into the nest as a result of dulosis. On the other hand, since rasilis is known to be a temporary social parasite, it is possible, though not likely, that the colony might have arisen through the simultaneous entry of a female of puberula and one of rasilis into the original altipetens colony. A thorough excavation of the colony lead to the finding of two females of puberula but no female of rasilis was seen. In this case I feel that it is permissible to utilize the negative evidence resulting from her absence and state that the rasilis workers had been secured through dulosis since, less than a hundred yards from the excavated nest, I subsequently found a puberula colony engaged in attacking a nest of the typical microgyna. The microgyna nest was built at the base of a 
small sage brush plant around the stem and lower branches of which the rather flat mound had been constructed. On the surface of the mound were numerous clusters of ants. Examination showed that these consisted of two or three microgyna workers industriously engaged in dragging away a worker of puberula. In no case did I see any dead raiders. Nevertheless the activities of the microgyna workers were effective if not lethal for, when their nest was opened, not a single raider was found inside.

Several interesting deductions may be drawn from the above data. In the first place it seems obvious that the rasilis workers present in the original puberula colony were obtained as the result of some unusual condition which enabled the raiders to enter a nest from which they would have ordinarily been excluded. In the second place we may safely conclude that the infrequent occurrence of members of the microgyna group in the nests of slavemakers is due to the defensive activities of the former and not to any discrimination on the part of the slave makers. This is entirely in keeping with the idea advanced by Dr. W. M. Wheeler (5) that the type of slaves which appear in the nests of dulotic species will be determined by the abundance and degree of docility of the enslaved species.

(2) The nest founding of Formica ulkei Emery.

While collecting in the Black Hills of South Dakota in September 1933 the author secured numerous specimens of $F$. ulkei Emery in the type locality, Hill City. Among these was a single female which had been adopted by a small colony of Formica fusca. It may be recalled that in his monograph of the genus Formica Dr. Wheeler postulated fusca as the temporary host of ulkei (6). The nest in which the female just mentioned was taken was a small one consisting of not more than three dozen fusca workers most of which were minims. It seems likely, therefore, that the nest-founding activities of ulkei differ in no essential respects from those of exsectoides, the female securing adoption by a depauperate queenless colony of the host species. It may be 
added that in the neighborhood of Hill City the nests of ulke $i$ are widely separated with little evidence for the formation of daughter colonies through migration. Further south, however, in the Custer State Park the author found areas in which there were several nests in close proximity. Although these multiple nest colonies are perhaps less numerous than the enormous groups formed by the eastern exsectoides there is ample evidence that ulkei does on occasion form daughter colonies by migration.

\section{LITERATURE CITED}

(1) Wheeler, W. M. An Annotated List of the Ants of New Jersey. Bull. Amer. Mus. Nat. Hist. Vol. XXI, No. XXIII, p. 386 (1905)

(2) Wheeler, W. M. Fauna of New England. List of the Formicidæ. Boston Soc. Nat. Hist. Occasional Papers No. 7, p. 9 (1906)

(3) Wheeler, W. M. Insects of Connecticut. Formicoidea. Bull. Conn. Nat. Hist. and Geo. Surv. No. 22, p. 589 (1916).

(4) Wheeler, W. M. The Occurrence of the Pavement Ant (Tetramorium cxspitum L.) in Boston. Psyche XXXIV, 1927, pp. 164-165.

(5) Wheeler, W. M. Ants. Columbia Univ. Press, p. 460 et seq. (1913).

(6) Wheeler, W. M. A Revision of the Ants of the Genus Formica. Bull. Mus. Comp. Zool. Vol. LIII, No. 10, p. 487 (1913). 

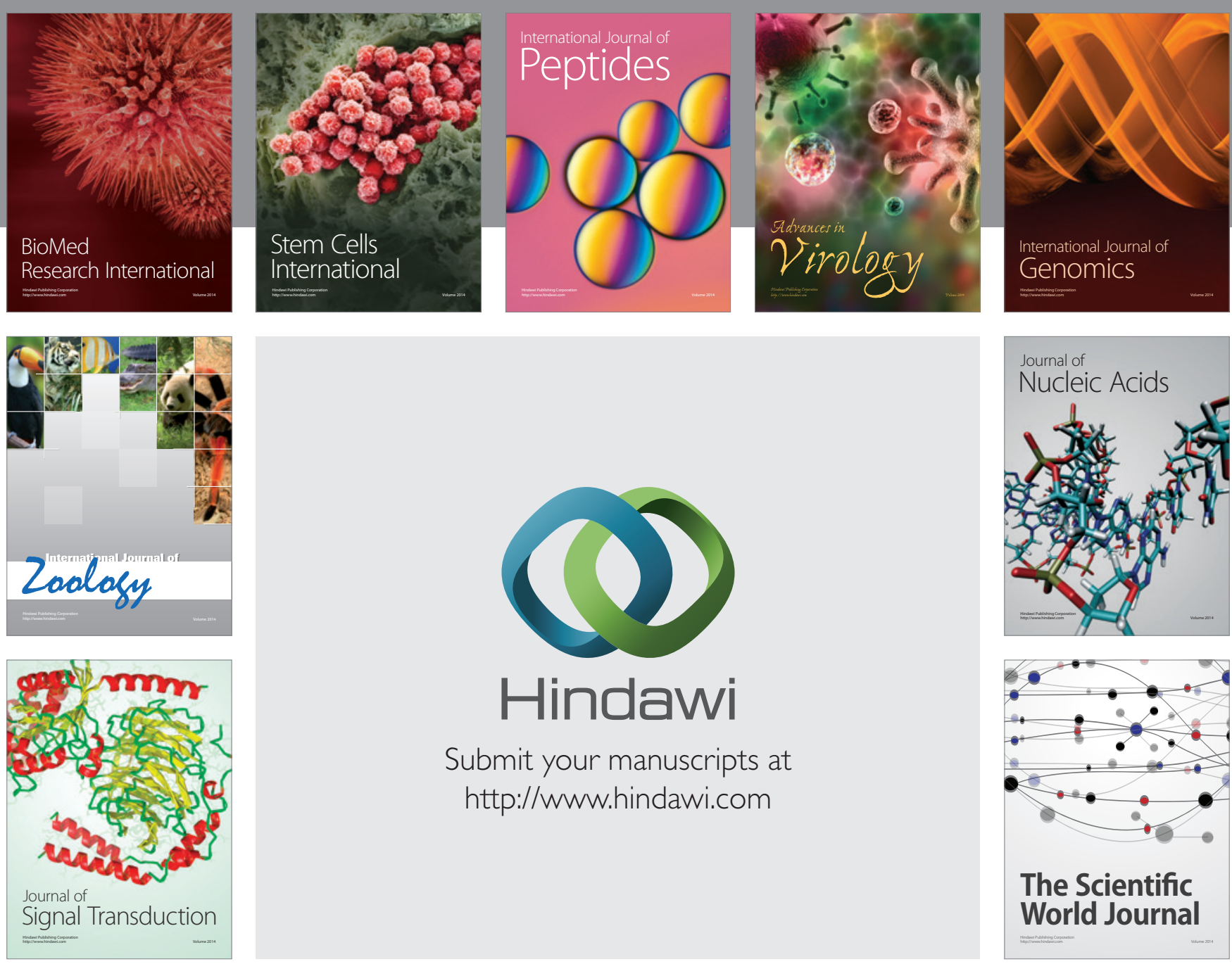

Submit your manuscripts at

http://www.hindawi.com
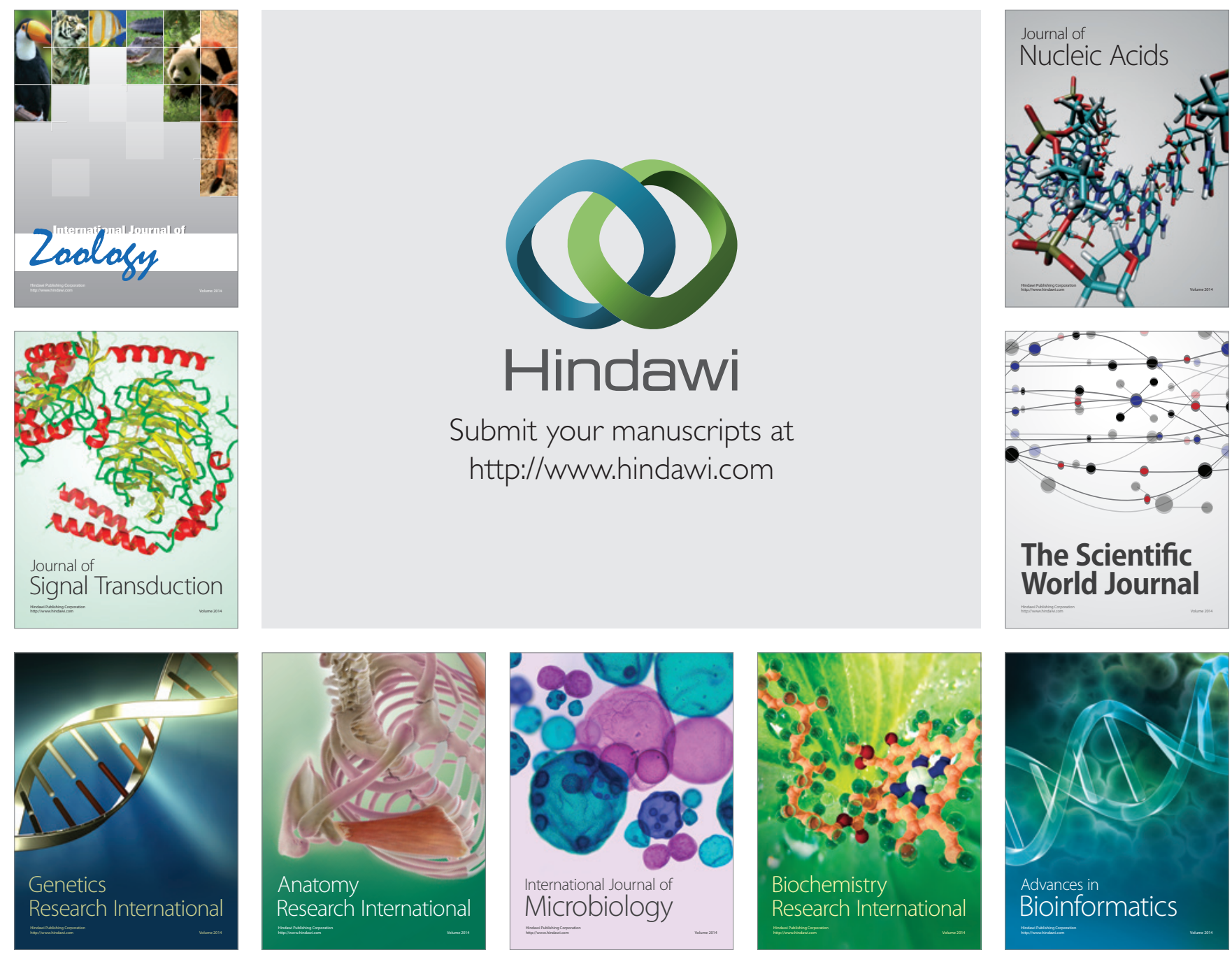

The Scientific World Journal
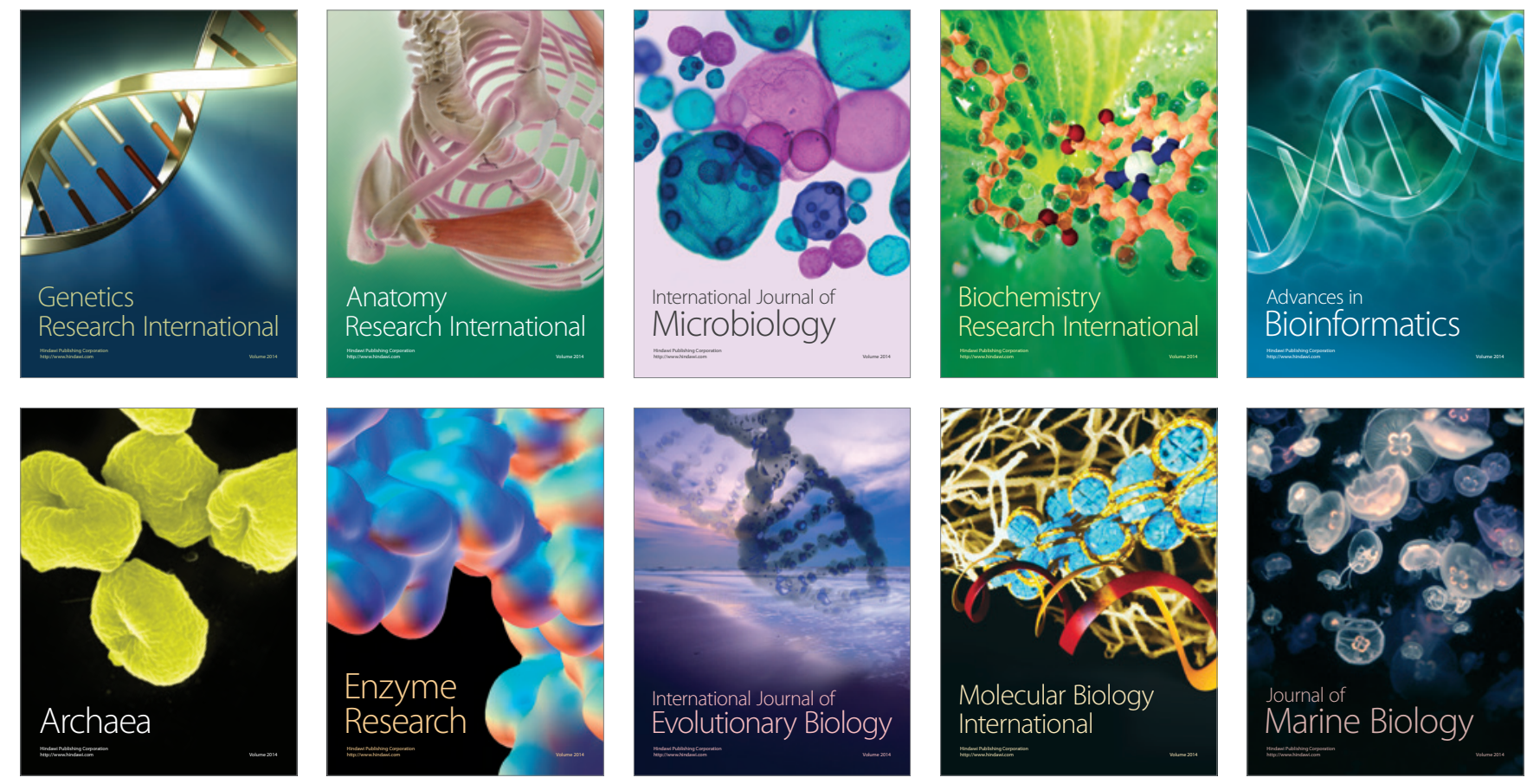